\title{
Use of Schiller's test versus Pap smear to increase detection rate of cervical dysplasias
}

\author{
Ramaraju H. E.*, Nagaveni Y. C., A. A. Khazi \\ Department of Obstetrics and Gynaecology, Vijaynagar Institute of Medical sciences, Bellary, Karnataka, India
}

Received: 23 February 2016

Revised: 24 February 2016

Accepted: 18 March 2016

\author{
*Correspondence: \\ Dr. Ramaraju H. E., \\ E-mail: drramaraju678@gmail.com
}

Copyright: (c) the author(s), publisher and licensee Medip Academy. This is an open-access article distributed under the terms of the Creative Commons Attribution Non-Commercial License, which permits unrestricted non-commercial use, distribution, and reproduction in any medium, provided the original work is properly cited.

\begin{abstract}
Background: Application of Lugol's iodine to cervix (Schiller's test) is named as Visual Inspection of cervix after applying Lugol's Iodine (VILI). VILI improves the detection rate of suspicious area over the cervix. The objectives of the study was to screening for early carcinoma or Dysplasia cervix by Schiller's test \& Pap smear and to compare the results of Schiller's test with Pap smear results.

Methods: The present prospective randomized control trials study was undertaken among 500 women aged between 25-65 years outpatient's Department of gynecology in Vijayanagar Institute of Medical Sciences (VIMS) Bellary. The study was undertaken during January 2007 to June 2008. Permission for the study was obtained from the College authorities prior to commencement.

Results: Out of total 500 patients screened for Pap smear and Schiller's iodine, majority were in the age group of 3140 years. Biopsy proven dysplasia was more common in patients with white discharge (10.8\%), post-menopausal bleeding (16.6\%) and in posts coital bleeding (15.3\%). 180 cases were Schiller's iodine test positive, out of which biopsy proven cases were more in non-specific chronic cervicitis $(68.88 \%)$ and rest seen in cervical epithelial abnormalities ( $7.7 \%$ ), Mild dysplasia (10\%), Moderate and Severe dysplasia 13\%. Cytological abnormalities were found in 48 (9.6\%), 180 cases were Schiller's iodine test positive (36\%). Among these 180 Schiller's positive cases 24 cases (13.33\%) were CIN2 and CIN 3 lesions. 42 patients were Schiller's test guided biopsy proven for cervical dysplasia, of which only 16 patients $(8.88 \%)$ were Pap smear positive. The sensitivity of Schiller's test and Pap smear were $97.67 \%$ and $38 \%$ respectively.

Conclusions: This study reveals that Schiller's test can be use full in low resource setting and in busy outpatient departments.
\end{abstract}

Keywords: Schiller's test, Dysplasia, Pap smear, Cervical Malignancy, VILI

\section{INTRODUCTION}

Cervical carcinoma is preceded for many years by cervical dysplastic changes or cervical intraepithelial neoplasia CIN. Non-invasive lesion which is quiescent may activate in future, may proliferate may become malignant. These dysplastic changes can be detected earlier by various screening methods. One among them is application of Lugol's iodine to cervix (Schiller's test) is named as Visual Inspection of cervix after applying
Lugol's Iodine (VILI). VILI improves the detection rate of suspicious area over the cervix. ${ }^{1}$

Walter Schiller an American emphasized that carcinoma of cervix can be diagnosed before invasion occurs and introduced the Schiller's test, using the Schiller's iodine. ${ }^{1}$ Applying Lugol's iodine over the cervix healthy epithelium containing glycogen stained mahogany brown colour, abnormal epithelium doesn't contain glycogen, therefore remains unstained. 
Increase availability and expertise Schiller's test is a useful screening test for early lesion of cancer of cervix where colposcope cannot be used for large number of people for screening purpose. ${ }^{2}$

In Indian women in rural areas are of low socioeconomic status, illiterate. Early marriages and multiparity are making them more prone for development of cervical cancer. They cannot gain access and approach to referral centers for cumbersome cervical cancer screening methods like Pap smear.

VILI in low resource settings can be used easily by health workers at rural set up. More number of women can be screened and then referred to higher centers for follow up. Therefore we can decrease the incidence of mortality of cervical cancer in Indian women. As it is easier to detect the colour pattern produced by iodine staining than acetic acid, Schiller's test is most useful as a screening test in rural areas where histopathological services are not available.

In order to reduce the frequency of false positive outcomes Dr. Sankaranarayanan prepared an atlas depicting the staining patterns associated with normal cervix, ectropion, polyps, inflammatory conditions, squamous metaplasia and neoplastic conditions. ${ }^{3-5}$

This inspired me to take up this study "Use of Schiller's test versus Pap smear to increase detection rate of cervical dysplasia". Though it is nonspecific test, it identifies nonspecific inflammation, CIN and invasive cancer. The objectives of study were: Screening for early carcinoma or Dysplasia cervix by Schiller's test \& Pap smear and to compare the results of Schiller's test with Pap smear results.

\section{METHODS}

The present Prospective randomized control trials study was undertaken among women aged between $25-65$ years outpatient's Department of gynaecology in Vijayanagar Institute of Medical Sciences (VIMS) Bellary. The study was undertaken during January 2007 to June 2008. Permission for the study was obtained from the College authorities prior to commencement.

\section{Sample size}

500 women aged between $25-65$ years were taken in the study.

\section{Inclusion criteria}

Age 25-65 years, history of persistence white discharge resistance to treatment, history of irregular bleeding or post coital bleeding, erosion or thickened white epithelial areas, and cytologically smears reported us inflammatory or dysplasia.

\section{Exclusion criteria}

Age group below 25 and above age 65, cases where obvious invasive carcinoma or visible cervical mass, all pregnant women puerperal women, recently aborted women, Active lower genital tract infection.

\section{Data collection method}

The objectives and methodology of the study were explained to those women who were included in the study. Apparently 500 women of those aged between 25 65 years who voluntarily willing for the examination were taken in this study. Willing patients were enrolled into the study information is obtained us for the proforma. Women coming for testing should have the screening procedure explained to them in detail. After explaining the procedure and taking informed consent, every effort made to ensure that she is fully relaxed and remains at ease during testing. The women is asked to lie down in a dorsal position and observe the external genitalia, perineal region for any excoriations, edema, vesicles, papules, sores, ulceration and warts.

The Cusco's speculum gently introduced and opened and the ectocervix examined. Pap smear was taken by scraping of cells from ectocervix by Ayre's spatula and endocervical smear by cotton tipped applicator. Smear was made by spreading on a glass slide and fixed in a coplin jar containing isopropyl alcohol. The cervix was painted with Lugol's iodine for few seconds with cotton swab with the help of sponge holder. After removing the swab cervix was inspected for any iodine non uptake areas in the form of pale or yellowish white areas, particularly in the transformation zone close to squamocolumnar junction. Punch biopsy taken from the non-uptake areas and sent for histopathological examination.

After application of Lugol's iodine the naked eye examination scored the findings as VILI Negative or VILI Positive with the help of an atlas and based on the criteria given below.

\section{Criteria for categorizing Schiller's test results}

Negative (-)

1. Normal cervix where squamous epithelium turns mahogany brown (or) black and the columnar epithelium does not change colour and remains pale.

2. Patchy, indistinct, ill-defined colorless (or) partially brown areas in the transformation zone.

3. Leopard skin appearance.

4. Thin yellow non-iodine uptake areas with angular (or) digitating margins, resembling geographical areas located far away from the squamocolumnar junction. 
Positive (+)

1. Well defined dense, thick bright mustard yellow (or) saffron-yellow iodine non uptake areas touching the squamocolumnar junction.

2. Circumorificial well defined thick dense yellow lesion, occupying large portion of the cervix.

3. Growth on the cervix turns yellow.

The cytology smears were fixed in 95\% alcohol and processed stained and read at the pathology department. Biopsy specimens were fixed in formaldehyde and sent to pathology department for histopathological examination.

\section{Data analysis}

Data collected was entered in Microsoft Office Excel and analysed by using SPSS version 13.0. Dependent variable frequencies, percentage, were calculated. The differences were considered as significant at a $\mathrm{p}$ value of $<0.05$.

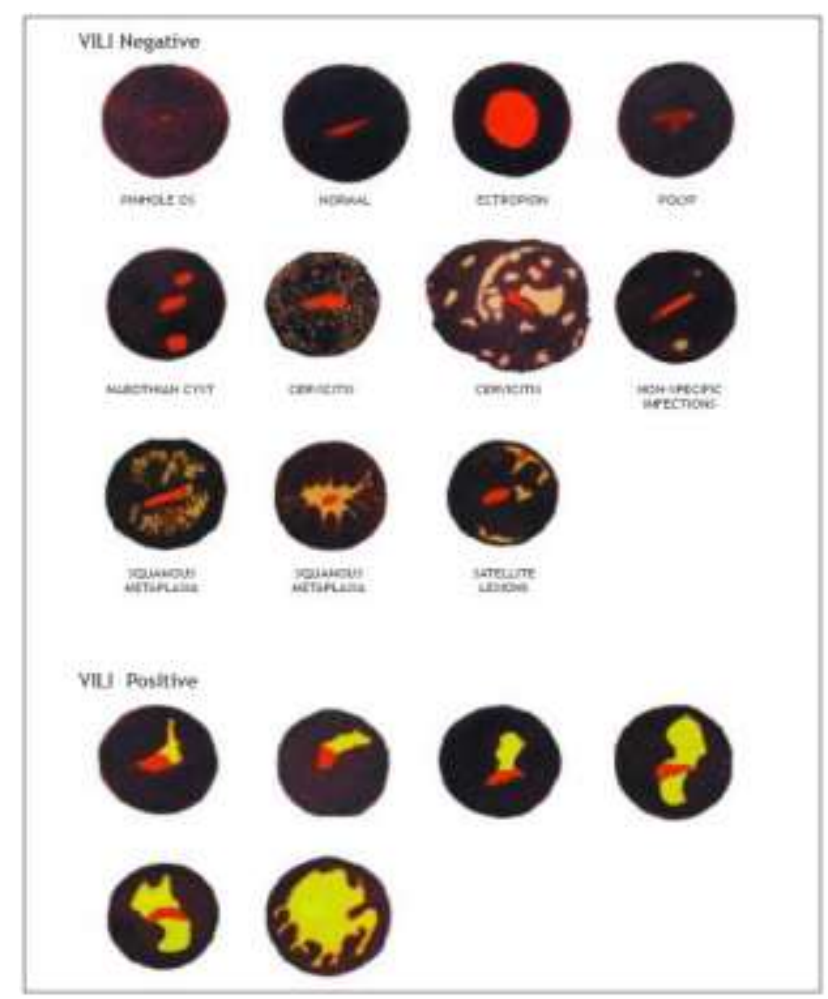

Figure 1: VILI positive and negative reading chart.

\section{RESULTS}

In this study 500 patients who were screened for precancerous lesions of cervix at Department of OBG MCH VIMS Bellary. An analysis was made with regards to socioeconomic status of the patients, age, parity, age at marriage, contraception use and clinical appearance of cervix and epithelial abnormalities of the cervix.

\section{Table 1: Schiller's iodine positive cases (180 cases)} and its directed biopsy.

\begin{tabular}{|c|c|c|}
\hline $\begin{array}{l}\text { Histopathological } \\
\text { examination biopsy report }\end{array}$ & No of patients & $\%$ \\
\hline $\begin{array}{l}\text { No of cervical epithelial } \\
\text { abnormalities }\end{array}$ & 14 & 7.7 \\
\hline $\begin{array}{l}\text { Chronic non-specific } \\
\text { cervicitis }\end{array}$ & 124 & 68.88 \\
\hline $\begin{array}{l}\text { Squamous metaplasia and } \\
\text { mild dysplasia }\end{array}$ & 18 & 10 \\
\hline Moderate dysplasia & 12 & 6.6 \\
\hline Severe dysplasia & 12 & 6.6 \\
\hline Total & 180 & 100 \\
\hline
\end{tabular}

Out of total 500 patients screened for Pap smear and Schiller's iodine, majority were in the age group of 31-40 years. $31 \%$ of patients out of total 500 patients in our study belong to low socio economic status and $30 \%$ in lower middle class, out of which 18 and 12 patients were biopsy positive for dysplasia in each group respectively and least in high socio economic status. Biopsy proven dysplasia was more common in patients with white discharge $(10.8 \%)$, post-menopausal bleeding (16.6\%) and in posts coital bleeding (15.3\%); however the number of patients were less with post-menopausal bleeding. Most of patients with dysplasia are women with more than two children $(58.88 \%)$. In our study cervical dysplasia was common in patients who got married at less than 20years.

In total number of 500 cases, 180 cases were Schiller's iodine test positive, out of which biopsy proven cases were more in nonspecific chronic cervicitis $(68.88 \%)$ and rest seen in cervical epithelial abnormalities $(7.7 \%)$, Mild dysplasia (10\%), Moderate and Severe dysplasia $13 \%$ (Table 1).

Table 2: Distribution of reference diagnosis by screening test (total no of patients 500).

\begin{tabular}{|lllll|}
\hline Screening test & Total no of patients & Normal/inflammatory/CIN1patients & CIN 2/CIN 3 lesions & \% \\
\hline Cytology positive & 48 & 36 & 12 & 9.6 \\
\hline Cytology negative & 452 & 440 & 12 & 90.4 \\
\hline Schiller's iodine positive & 180 & 138 & 24 & 36 \\
\hline Schiller's iodine negative & 320 & 320 & 01 & 64 \\
\hline
\end{tabular}


Table 3: Comparison of Schiller's test positive and negative Pap smear results in 180 patients.

\begin{tabular}{|lll|}
\hline Name of screening test & $\begin{array}{l}\text { Biopsy positive } \\
\text { total dysplasia }\end{array}$ & $\%$ \\
\hline Schiller's test positive & 42 & 23.33 \\
\hline PAP smear positive & 16 & 8.88 \\
\hline PAP smear negative & 26 & 14.44 \\
\hline
\end{tabular}

The reference diagnosis was based on Histopathology of biopsy specimen taken after the application of Schiller's iodine. Cytology was considered as positive if there are atypical cells CIN 1-3 or invasive cancer Table 2 . In total 500 cases cytological abnormalities were found in 48 (9.6\%), 180 cases were Schiller's iodine test positive (36\%). Among these 180 Schiller's positive cases 24 cases (13.33\%) were CIN2 and CIN 3 lesions. Histopathological examination biopsied specimen after
Schiller's test is taken as reference diagnosis as gold standard. The detection rate of Schiller's test in a total 500 cases is $4.8 \%$ and that of Pap smear is $2.4 \%$.

Table 4: Cytology positive cases out of Schiller's negative.

\begin{tabular}{|lll|}
\hline Dysplasia & Cytology positive & $\%$ \\
\hline Mild dysplasia & 20 & 62.5 \\
\hline Moderate dysplasia & 11 & 34.37 \\
\hline Severe dysplasia & 1 & 3.12 \\
\hline Total & 32 & 100 \\
\hline
\end{tabular}

Out of 180 Schiller's test positive patients, 42 patients were Schiller's test guided biopsy proven for cervical dysplasia, of which only 16 patients $(8.88 \%)$ were Pap smear positive. Therefore the Schiller's test detects additional $14 \%$ cases dysplasia Table 3.

Table 5: Comparison of diagnostic values of Schiller's test and Pap smear test.

\begin{tabular}{|llllll|}
\hline Screening test & Sensitivity & Specificity & NPV & PPV & Diagnostic accuracy (\%) \\
\hline Schiller's test & $97.67 \%$ & $69 \%$ & $99.68 \%$ & $23 \%$ & 72.40 \\
\hline Pap smear/Cytology & $38 \%$ & $94 \%$ & $84.14 \%$ & $73 \%$ & 92 \\
\hline
\end{tabular}

Out of 320 Schiller's negative cases, 32 cases (10\%) were cytology positive and majority were mild dysplasia. Out of 32 cytology positive patients among 320 Schiller's negatives, only one patient $(3.12 \%)$ was biopsy positive Table 4.

The sensitivity of Schiller's test and Pap smear were $97.67 \%$ and $38 \%$ respectively. The corresponding specificity was $69 \%$ and $94 \%$. PAP smear has higher false negative rate that is $68 \%$. This table shows that Schiller's iodine application yields better results Table 5 .

\section{DISCUSSION}

The present study is taken up to make use of Schiller's test as a method for screening for carcinoma of cervix at rural setups where histopathological services are not available. This study shows that it is a suitable alternative approach to cervical cytology in low resource settings.

Visual inspection of cervix is a more promising approach which has become popular in the period 1992-1994. Bennett and Herman proposed two methods of visual inspection. One is Visual inspection with Acetic acid (VIA) and another is visual inspection with Lugol's iodine (VILI) similar to Schiller's test. These two methods were equivalent and yield good results than pap's smear procedure. They are also cheaper so that under low resource setting large number of women can be screened.
Table 6: Cervical epithelial abnormalities in relation to symptoms by other studies.

\begin{tabular}{|lll|}
\hline $\begin{array}{l}\text { Name of the } \\
\text { study }\end{array}$ & $\begin{array}{l}\text { White discharge } \\
\%\end{array}$ & $\begin{array}{l}\text { Menstrual } \\
\text { irregularities \% }\end{array}$ \\
\hline $\begin{array}{l}\text { Pankaj Desai } \\
\text { et al }\end{array}$ & 31.89 & 23.75 \\
\hline $\begin{array}{l}\text { Pabmanabhan } \\
\text { et al }\end{array}$ & 68.7 & 51.2 \\
\hline Present study $^{7}$ & 10.8 & 15.3 \\
\hline
\end{tabular}

In the present study, majority of patients having dysplasia, $42 \%$ by cytology and $66 \%$ by Schiller's test belong to age group of 31-40 years. In a study conducted by Desai $\mathrm{P}$ et al $40.5 \%$ women belongs to age group of 30-40 years. ${ }^{6}$

Table 7: Relation of dysplasia to age at marriage by different studies.

\begin{tabular}{|lll|}
\hline Name of the study & A ge at marriage & $\%$ \\
\hline${\text { Wahi et } \mathrm{al}^{8}}^{8}$ & $16 \mathrm{yr}$ & $84 \%$ \\
\hline Bhatla et $\mathrm{al}^{9}$ & $19 \mathrm{yr}$ & $54 \%$ \\
\hline Present study & $<20 \mathrm{yr}$ & $88.88 \%$ \\
\hline
\end{tabular}

The above observations and present study indicates that women got married at younger age are more likely to develop dysplastic changes in cervical epithelium. 
Table 8: The detection rate of dysplasia by Pap smear by various studies.

\begin{tabular}{|l|l|l|}
\hline \multirow{3}{*}{ Screening test } & Name of the study & Incidence \\
\hline \multirow{3}{*}{ Pap smear } & ${\text { Bhatla et } \mathrm{al}^{9}}^{9}$ & $5 \%$ \\
\cline { 2 - 3 } & Sankarnarayanan et $\mathrm{al}^{5}$ & $2.8 \%$ \\
\cline { 2 - 3 } & Present study & $2.4 \%$ \\
\hline
\end{tabular}

According to Jeffcoat's, the cervix of adolescent girl is more prone for dysplasia. ${ }^{10}$ During this metaplastic process, if cells are exposed to nuclear material of spermatozoa, they undergo atypical changes. Hence more importance is given in screening for women who got married at younger age.

Table 9: The detection rate of cervical dysplasia by Schiller's test by various studies.

\begin{tabular}{lll} 
Screening test & Name of the study & Incidence \\
Schiller's test & Sankarnarayanan et $\mathrm{al}^{5}$ & $2.9 \%$ \\
\cline { 2 - 3 } & Present study & $4.8 \%$ \\
\hline
\end{tabular}

The detection rate of dysplasia by Pap smear is $2.4 \%$ and that of Schiller's test is $4.8 \%$. In the study conducted by Dr Sankarnarayanan et al detection rate was $2.8 \%$ for cytology and $2.9 \%$ for Schiller's test. This reveals that Schiller's test is equally effective and detects $2.4 \%$ more cases than Pap smear (Table 8).

In a total of 500 patients 180 patients that is $36 \%$ were Schiller's positive cases out of these Schiller's positive were $16 \%$ were biopsy positive for CIN $2 / \mathrm{CIN} 3$ in a study by Sankarnarayanan et al. The incidence of Schiller's positive cases is $17.7 \%$.

In a total 180 patients with Schiller's positive, those who have negative Pap smear and biopsy positive for dysplasia is $14.44 \%$. Therefore Schiller's test detects additional $14.44 \%$ cases of dysplasia. In the study by Singh VK concluded that Schiller's test detects additional $14 \%$ cases of dysplasia than Pap smear. ${ }^{11}$ In this study Schiller's test more sensitive $(97.67 \%)$ than Pap smear $(38 \%)$ and Pap smear is more specific

\section{CONCLUSION}

This study reveals that Schiller's test can be use full in low resource setting and in busy outpatient departments. More number of women can be screened in the same setting thereby referral can be done in suspicious cases; therefore we can reduce the incidence of carcinoma cervix and mortality of women. However large studies needs further for confirmation of results.

\section{ACKNOWLEDGEMENTS}

I would like to express my profound gratitude to all the participants for their co-operation and for their immense faith they reposed in me.

Funding: No funding sources

Conflict of interest: None declared

Ethical approval: The study was approved by the Institutional Ethics Committee

\section{REFERENCES}

1. Padubidri VG, Daftary SN. Shaw's text book of Gynecology, $14^{\text {th }}$ edition, Elser publisher; pp. 359366.

2. Dawn CS. UG \& PG Text book Gynecology and contraception, $13^{\text {th }}$ edition, pp. 399.

3. Edward Holl E, Walton L. Dysplasia of cervix. 1968100(5):662-71.

4. Sankaranarayanan R, Budukh A, Rajakumar R. Effective screening programs for cervical cancer in low and middle income developing countries. Bull world Health organ. 2001;79:954-62.

5. Sankaranarayanan R, Wesley R. A practical manual on visual screening for cervical neoplasia: IARC Technical publication No. 41. Lyon international agency research on cancer, IARC press, 2003.

6. Desai P, Desai M, Desai M. Cytopathology of uterine cervixusing the Bethesda system in 2800 screening individuals. J Obstet Gynecol of India. 1993;43:403-7.

7. Padmanabhan H, Oumachigui A, Sankaran V, Rajaram P. A study of 80 cases of cervical intraepithelial neoplasia in a developing country. J Obstet Gynecol India. 1998:107-11.

8. Wahi PN, Mali S, Luthra UK. Factors influencing cancer of the uterine cervix in North India. 1969;23(5):1221-6.

9. Bhatla N, Mukhopadhyay A, Kriplani A. Evaluation of adjunctive tests for cervical cancer screening in low resource settings. Indian J Cancer. 2007;44:51-5.

10. Jeffcoate's principles of Gynecology $6^{\text {th }}$ edition 2001, pp. 392.

11. Singh VK, Bhagoliiwal A, Kapoor A. Use of Schiller's test of cervix to increase detection rate of cervical dysplasias. JOGI. 2001:51;392.

Cite this article as: Ramaraju HE, Nagaveni YC, Khazi AA. Use of Schiller's test versus Pap smear to increase detection rate of cervical dysplasias. Int J Reprod Contracept Obstet Gynecol 2016;5:144650 . 